Original Article

\title{
The correlation between calcaneal valgus angle and asymmetrical thoracic-lumbar rotation angles in patients with adolescent scoliosis
}

\author{
Jaeyong Park ${ }^{1)}$, Sang Gil LeE ${ }^{2)}$, Jonguin BaE ${ }^{3)}$, Jung Chul Lee ${ }^{4}{ }^{*}$ \\ 1) Institute of Sports Health Science, Sunmoon University, Repubic of Korea \\ 2) Schroth Corrective Exercise Center, Repubic of Korea \\ 3) Jeollanamdo Sports Council, Repubic of Korea \\ 4) Department of Exercise Prescription, Dongshin University: 185 Geonjae-Ro, Naju, Jeonnam \\ 520-714, Repubic of Korea
}

\begin{abstract}
Purpose] This study aimed to provide a predictable evaluation method for the progression of scoliosis in adolescents based on quick and reliable measurements using the naked eye, such as the calcaneal valgus angle of the foot, which can be performed at public facilities such as schools. [Subjects and Methods] Idiopathic scoliosis patients with a Cobb's angle of $10^{\circ}$ or more (96 females, 22 males) were included in this study. To identify relationships between factors, Pearson's product-moment correlation coefficient was computed. The degree of scoliosis was set as a dependent variable to predict thoracic and lumbar scoliosis using ankle angle and physique factors. Height, weight, and left and right calcaneal valgus angles were set as independent variables; thereafter, multiple regression analysis was performed. This study extracted variables at a significance level $(\alpha)$ of 0.05 by applying a stepwise method, and calculated a regression equation. [Results] Negative correlation $(\mathrm{R}=-0.266)$ was shown between lumbar lordosis and asymmetrical lumbar rotation angles. A correlation $(\mathrm{R}=0.281)$ was also demonstrated between left calcaneal valgus angles and asymmetrical thoracic rotation angles. [Conclusion] Prediction of scoliosis progress was revealed to be possible through ocular inspection of the calcaneus and Adams forward bending test and the use of a scoliometer.
\end{abstract}

Key words: Scoliosis, Asymmetrical lumbar rotation angle, Asymmetrical thoracic rotation angle

(This article was submitted Jul. 17, 2015, and was accepted Sep. 25, 2015)

\section{INTRODUCTION}

Scoliosis is a 3-dimensional vertebral transformation, accompanied by rotation and lateral deviation of each vertebra $^{1)}$. Scoliosis most often develops in childhood (at around 10 years of age) becoming apparent in adolescence, and is reported to deteriorate rapidly ${ }^{2}$. An especially fast progression of scoliosis is shown during the adolescent period, when growth is the most active before it is completed, which has worsened in recent years due to a lack of physical activity and due to the prolonged use of smartphones and PCs in awkward postures ${ }^{3)}$

In cases of scoliosis that escape detection, patients complain of decreased social activity and backache, primarily due to changes in body shape, which are often accompanied by breathing difficulties. In extreme cases, the possibility of death due to a decline in cardiac and pulmonary function

*Correspondence author. Jung Chul Lee (E-mail: channel365@hanmail.net)

C2015 The Society of Physical Therapy Science. Published by IPEC Inc. This is an open-access article distributed under the terms of the Creative Commons Attribution Non-Commercial No Derivatives (by-ncnd) License $<$ http://creativecommons.org/licenses/by-nc-nd/3.0/>. and respiratory failure increases, and surgery is inevitably necessary ${ }^{4,5)}$. Thus, early detection is paramount, because the prognosis of undetected scoliosis is poor ${ }^{6)}$. The main methods used to diagnose scoliosis at clinical sites are Cobb's angle, Risser sign, vertebral stability and rotation of vertebrae (Perdriolle or Nash-Moe method) ${ }^{7}$. Most of these methods use expensive magnetic resonance imaging (MRI) equipment. In view of the characteristics of scoliosis, patients do not complain of limitations to physical movement or discomfort at early stages, and only receive a diagnosis at clinical sites after vertebral arrangement progression becomes serious. Many studies have found that examination at an early age (11 or 12 years) is appropriate because early screenings for scoliosis enable treatment to be given at a critical point in time ${ }^{8)}$.

Although there are many diagnostic methods that use high-priced cutting-edge equipment, active treatment following quick early detection at schools or other youth facilities is the most efficient evaluation method and means of enabling treatment ${ }^{9)}$. In addition to examination methods that use harmful radiation, location comparisons of the shoulders, chest, waist, and pelvis by ocular inspection; pulmonary function tests; and measurements using a scoliometer along with forward bending, are also reliable measurement methods ${ }^{10)}$. 
Table 1. Physical characteristics of subjects

\begin{tabular}{lcccc}
\hline $\begin{array}{l}\text { Item } \\
\text { class }\end{array}$ & Age & Height & Weight & BMI \\
\hline Female $(\mathrm{N}=96)$ & $15.2 \pm 2.4$ & $160.7 \pm 5.5$ & $47.9 \pm 6.0$ & $18.5 \pm 1.9$ \\
Male $(\mathrm{N}=22)$ & $16.5 \pm 2.4$ & $174.9 \pm 7.3$ & $64.3 \pm 10.2$ & $20.9 \pm 2.4$ \\
Total $(\mathrm{N}=118)$ & $15.5 \pm 2.4$ & $163.4 \pm 8.0$ & $50.9 \pm 9.5$ & $18.9 \pm 2.2$ \\
\hline
\end{tabular}

BMI: body mass index

Table 2. The mean and standard deviation of scoliosis related variables

\begin{tabular}{lccccc}
\hline $\begin{array}{l}\text { Item } \\
\text { class }\end{array}$ & ATRA & ALRA & LL & LCVA & RCVA \\
\hline Female $(\mathrm{N}=96)$ & $7.1 \pm 3.4$ & $6.9 \pm 4.0$ & $41.6 \pm 6.6$ & $7.9 \pm 3.8$ & $7.4 \pm 3.9$ \\
Male $(\mathrm{N}=22)$ & $6.5 \pm 2.9$ & $5.2 \pm 3.8$ & $41.6 \pm 7.5$ & $6.7 \pm 3.7$ & $6.9 \pm 4.5$ \\
Total $(\mathrm{N}=118)$ & $7.0 \pm 3.3$ & $6.6 \pm 4.0$ & $41.6 \pm 6.7$ & $7.7 \pm 3.8$ & $7.3 \pm 4.0$ \\
\hline
\end{tabular}

ATRA: asymmetry thoracic rotation angle $\left({ }^{\circ}\right)$; ALRA: asymmetry lumbar rotation angle $\left({ }^{\circ}\right)$; LL: lumbar lordosis $\left({ }^{\circ}\right)$; LCVA: left calcaneal valgus angle $\left({ }^{\circ}\right)$; RCVA: right calcaneal valgus angle $\left({ }^{\circ}\right)$

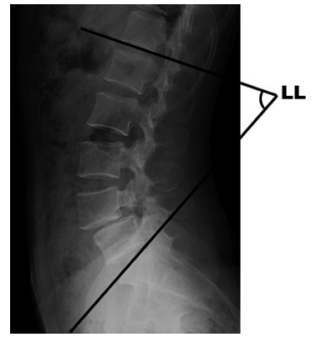

Fig. 1. Total lumbar lordosis (LL) measurement

This study carried out a correlation analysis based on quick predictive methods with the naked eye, such as the calcaneal valgus angle, the calcaneal angle and Adam's forward bending test, in front-line facilities such as schools, then checked those methods' preciseness and reliability in order to present the most effective evaluation method. The purpose of this study was to detect adolescent scoliosis early, to prevent unnecessary surgeries and aid proper treatment.

\section{SUBJECTS AND METHODS}

This study targeted adolescents who received diagnoses of idiopathic scoliosis with $10^{\circ}$ or more of Cobb's angle on whole spine AP X-ray examination from rehabilitation medicine specialists. After potential subjects were informed of the objectives and procedures of the experiment, those who understood the purpose of the study, and agreed to actively participate in the work were enrolled in the study. This study received approval from the Institutional Review Board (IRB) of Clinical Test at Gwangju Oriental Hospital of Dongshin University on September 9, 2013 (IRB NO: DSGOH-017). This study selected those subjects who had no experience with conservative treatment for scoliosis in the past, those who had no other problems in terms of orthopedics, and those with no history of cardiac problems and/or pulmonary disease. The participants' physical properties are

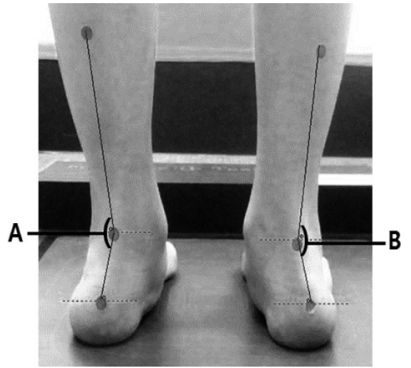

Fig. 2. Calcaneal valgus angle measurement (A: left calcaneal valgus angle $\left[{ }^{\circ}\right]$, B: right calcaneal valgus angle $\left[{ }^{\circ}\right]$ )

shown in Table 1.

For the Adam's forward-bending test, participants placed their feet together, allowing their arms to hang naturally, and bent their upper bodies forward $90^{\circ}$ from the standing position. Examiners used visual evaluations, with their eyes at levels equal to those of the participants' backs, and measured asymmetrical thoracic rotation angles (ATRA) and asymmetrical lumbar rotation angles (ALRA) at the rib hump and lumbar hump using a scoliometer (USA) (Table 2) ${ }^{11)}$.

Participants were instructed to stand straight in order to view lumbar lordosis angles from the sagittal plane, bending the upper limbs forward by $90^{\circ}$, and keeping the eyes forward. Side radiographs were taken at $1.5 \mathrm{~m}$ distance from the cassette. Lumbar lordosis angles were used to calculate crossed angles by drawing each line on the upper end-plate of the first lumbar vertebra and the upper end-plate of the first sacral vertebra, giving the calculated angle of the size of the curvature as shown in Fig. $1^{12)}$.

For the analysis of the calcaneal valgus angles, this study performed a plumb line test ${ }^{13}$, as shown in Fig. 2, using the Body Balance Index System, STEPS ${ }^{\circledR}$, Korea. This study measured the angle between the mid-calcaneal axis and the mid-talar axis.

This study computed the mean and standard deviation 
Table 3. Summary of stepwise regression procedure for dependent variable ATRA

\begin{tabular}{lccc}
\hline Step & Partial R2 & Model R2 & C(p) \\
\hline BMI $^{* * *}$ & 0.13 & 0.13 & 4.48 \\
LCVA $^{*}$ & 0.04 & 0.17 & 1.32 \\
\hline
\end{tabular}

BMI: body mass index; LCVA: left calcaneal valgus angle $\left({ }^{\circ}\right) ;{ }^{* * *} \mathrm{p}<0.0001(\mathrm{~F}=16.11),{ }^{*} \mathrm{p}<0.05(\mathrm{~F}=5.24)$

Table 5. Summary of stepwise regression procedure for dependent variable ALRA

\begin{tabular}{lccc}
\hline Step & Partial R2 & Model R2 & $\mathrm{C}(\mathrm{p})$ \\
\hline LL** & 0.07 & 0.07 & 1.46 \\
BMI & 0.02 & 0.09 & 1.35 \\
\hline BMI: body mass index; & LL: lumbar lordosis $\left(^{\circ}\right),{ }^{* *} \mathrm{p}$ \\
$<0.001(\mathrm{~F}=7.47)$
\end{tabular}

of the factors related with scoliosis, and extracted variables with correlation at significance level $\alpha$ of 0.05 . This set the degree of scoliosis as a dependent variable to predict thoracic and lumbar scoliosis using ankle angles and physique factors, and set height, weight, and left and right calcaneal ankle angles as independent variables, and then performed a multiple regression analysis to find meaningful explanatory variables. Variables were extracted at a significance level $(\alpha)$ of 0.05 by applying a stepwise method, and then the regression equation was calculated.

\section{RESULTS}

Tables 3 and 4 show the results of variable extraction and regression equations using a stepwise method of multiple regression analysis in order to predict thoracic scoliosis through height, weight, BMI, and left and right calcaneal valgus angles.

As shown in Table 3, the variables that could predict only thoracic scoliosis were selected by applying the stepwise method; thereby, BMI and left calcaneal valgus angles were selected. BMI and left calcaneal valgus angles explained $17 \%$ of ATRA, and were statistically significant variables $(\mathrm{p}<0.05)$.

To estimate ATRA as shown in Table 4, this study set BMI and left calcaneal valgus angles as independent variables, and thoracic scoliosis angles as dependent variables, and constructed a regression equation. The root mean square error (RMSE) was $1.48^{\circ}$; therefore, BMI and left calcaneal valgus angles were effective variables to predict thoracic scoliosis $(\mathrm{p}<0.05)$.

Tables 5 and 6 show the results of extraction of variables and the regression equation using stepwise multiple regression analysis methods in order to predict the degree of lumbar scoliosis through height, weight, BMI and left and right ankle valgus angles.

As shown in Table 5, as the result of extracting the variables that can predict lumbar scoliosis by applying stepwise multiple regression analysis, lumbar lordosis and BMI were selected. The two variables explained $9 \%$ of ALRA, and
Table 4. Multiple regression analysis for predicting ATRA

\begin{tabular}{lccc}
\hline Variable & $\begin{array}{c}\text { Parameter } \\
\text { estimate }\end{array}$ & $\begin{array}{c}\text { Standard } \\
\text { error }\end{array}$ & Type II SS \\
\hline Intercept $^{* * *}$ & 14.19 & 2.72 & 245.88 \\
BMI $^{* *}$ & -0.45 & 0.13 & 106.79 \\
LCVA $^{*}$ & 0.18 & 0.08 & 47.51 \\
\hline \multicolumn{4}{c}{ ATRA $=14.19-0.45228 \times$ BMI $+0.17 \times$ LCVA } \\
\hline
\end{tabular}

BMI: body mass index; ATRA: asymmetry thoracic rotation angle $\left({ }^{\circ}\right)$; LCVA: left calcaneal valgus angle $\left({ }^{\circ}\right) ; * * *$ p $<0.0001(\mathrm{~F}=27.13), * * \mathrm{p}<0.001(\mathrm{~F}=11.78), * \mathrm{p}<0.05(\mathrm{~F}=5.24)$

Table 6. Multiple regression analysis for predicting ALRA

\begin{tabular}{|c|c|c|c|}
\hline Variable & $\begin{array}{c}\text { Parameter } \\
\text { estimate }\end{array}$ & $\begin{array}{c}\text { Standard } \\
\text { error }\end{array}$ & Type II SS \\
\hline Intercept ${ }^{* * *}$ & 17.23 & 3.72 & 324.68 \\
\hline BMI & -0.27 & 0.18 & 32.49 \\
\hline $\mathrm{LL}^{*}$ & -0.13 & 0.06 & 76.61 \\
\hline \multicolumn{4}{|c|}{ ALRA $=17.23-0.2696 \times \mathrm{BMI}-0.13 \times \mathrm{LL}$} \\
\hline
\end{tabular}

BMI: body mass index; ALRA: asymmetry lumbar rotation angle $\left({ }^{\circ}\right)$; LL: lumbar lordosis $\left({ }^{\circ}\right),{ }^{* * *} \mathrm{p}<0.0001(\mathrm{~F}=21.48)$, $* \mathrm{p}<0.05(\mathrm{~F}=5.07)$

were statistically significant variables $(\mathrm{p}<0.05)$.

BMI and lumbar lordosis were as independent variables, and ALRA was set as a dependent variable to estimate ALRA, formulating the regression equation shown in Table 6 . The RMSE of estimation was $1.68^{\circ}$, therefore, the y-intercept was not zero $(p<0.0001)$, and lumbar lordosis was an effective variable for predicting lumbar scoliosis $(\mathrm{p}<0.05)$.

\section{DISCUSSION}

This study sought to identify degrees of scoliosis through the left and right calcaneal valgus angles, which can be observed with the naked eye without radiation techniques, and by using a scoliometer, with which measurements can easily be conducted. To enhance the reliability of this study, correlations were analyzed with each variable by additionally associating lumbar lordosis in the sagittal plane.

Ultimately, a negative correlation between lumbar lordosis (LL) and ALRA was revealed $(\mathrm{R}=-0.266)$. Compensation for this can be revealed through observing the degree of asymmetry in the tuberosity of the calcaneus. This is consistent with other studies ${ }^{14)}$ which found that imbalances are revealed in the sagittal plane. Compensation can be divided into two, namely, intraspinal compensation and extraspinal compensation. Intraspinal compensation is further divided into thoracic compensation and pelvic compensation. Due to intraspinal compensation, muscle function changes occur, resulting in hip, lumbar and cervical pain, while proper standing positions cannot be maintained ${ }^{15}, 16$ ).

The greatest degree of LL is found at the third lumbar vertebra, fourth lumber vertebra, or at the disk between them. Lumbar segment lordosis starts between the first and second lumbar vertebrae, and gradually increases in the lower section. It was found that the greatest degree of seg- 
ment lordosis is found between the fourth and fifth lumbar vertebrae, and the angle between the fifth and first lumbar vertebrae accounts for $60 \%$ of total lordosis ${ }^{12}$. The pelvic tilt is the angle made by the line connecting the center of the sacral vertebral superior endplate and hip axis with the central plumb line, and is a location indicator reflecting pelvic compensation mechanisms when there are sagittal plane imbalances ${ }^{17)}$. From recent studies, it was revealed that the shape of the pelvis is important in in determining the curve of the sagittal plane ${ }^{17-19)}$.

Vialle et al. ${ }^{19)}$ revealed that some correlation exists between pelvic incidence angles and LL in normal individuals. This assertion nearly matched the findings of this study, in that significant correlation exists between lumbar lordosis angles and ALRA.

This study revealed that the left calcaneal valgus angle has a correlation with ATRA $(\mathrm{R}=0.282)$.

When the left ankle arch collapses causing flat feet, and both shoulders become imbalanced, scoliosis appears to develop. Namely, imbalance from the feet affects the legs, pelvis and vertebrae; therefore, scoliosis is believed to be resultant. According to a preceding study, when load is added to a specific lower limb, energy consumption increases. This energy consumption increase was reported to increase more when it was added to the end of the lower limb, rather than close to the trunk, despite the same weight ${ }^{20)}$. Scoliosis is a disease in which 3-dimensional transformation of the vertebrae bend together to one side with vertebral rotation of one foot's load, arising from an imbalance of the feet; therefore, it was reported that a change of the angle supporting the body weight, including shoes, can affect the prognosis of the disease ${ }^{21)}$. Postural asymmetries are also associated with the risk of progression in idiopathic scoliosis. Scoliotic curves are commonly seen with right and left anatomical leg length differences ${ }^{22}$. The pelvic obliquity attributable to rotational malalignment results in compensatory curves of the spine or the accentuation of any pre-existing curves. Carole et al. ${ }^{23)}$, tested the reliability of a quantitative clinical posture assessment tool among persons with idiopathic scoliosis. The dependability coefficients $(\varphi)$ for posture indices are presented in the tibiocalcaneal angles ( $\mathrm{L}$ and $\mathrm{R} ; \varphi=0.51$ and 0.53 , respectively). This means that checking feet stability is important when examining scoliosis ${ }^{24)}$. According to 3-dimensional analysis results, it was reported that functional shoes are helpful to vertebrae, especially for lumbar muscular strength consolidation and vertebral health, through the improvement of feet stability ${ }^{25)}$.

Based on the results of this study and the many preceding studies, the progress of scoliosis can be predicted to some degree, depending on visual checks of the sole arch shape, tuberosity of the calcaneus, Adam's forward bending test, and the use of a scoliometer. Idiopathic scoliosis develops during adolescence and progresses rapidly ${ }^{26}$, and therefore correction becomes difficult if the treatment window passes. Therefore, it is important to diagnose scoliosis early ${ }^{27)}$. If scoliosis is diagnosed in its early stages through prompt examination and evaluation at schools or other facilities, curvature progression and unnecessary surgeries can be prevented through conservative treatment with walking aids and/or exercise, when curvatures are slight ${ }^{28)}$.
This study had some limitations. First, calcaneal valgus angles and asymmetrical thoracic-lumbar rotation angles were only assessed in patients with adolescent scoliosis; there was no control group. Moreover, direct analysis of the correlations between Cobb angles and calcaneal valgus angles and asymmetrical thoracic-lumbar rotation angles was not performed. Therefore, it is unlikely that the study's results can be generalized. Future studies will be required to classify major curvatures in detail, and to analyze the relationship between Cobb angles, asymmetrical thoraciclumbar rotation angles and calcaneal valgus angles, the results of which may contribute to streamlined predictions and evaluations of idiopathic scoliosis.

\section{ACKNOWLEDGEMENT}

This work was supported by the National Research Foundation of Korea Grant funded by the Korean Government (NRF-2013-S1A5B5A01-029641).

\section{REFERENCES}

1) Fusco C, Zaina F, Atanasio S, et al.: Physical exercises in the treatment of adolescent idiopathic scoliosis: an updated systematic review. Physiother Theory Pract, 2011, 27: 80-114. [Medline] [CrossRef]

2) Suh SW, Modi HN, Yang JH, et al.: Idiopathic scoliosis in Korean schoolchildren: a prospective screening study of over 1 million children. Eur Spine J, 2011, 20: 1087-1094. [Medline] [CrossRef]

3) Giampietro PF, Blank RD, Raggio CL, et al.: Congenital and idiopathic scoliosis: clinical and genetic aspects. Clin Med Res, 2003, 1: 125-136. [Medline] [CrossRef]

4) Asher MA, Burton DC: Adolescent idiopathic scoliosis: natural history and long term treatment effects. Scoliosis, 2006, 1: 2. [Medline] [CrossRef]

5) Weinstein SL, Dolan LA, Spratt KF, et al.: Health and function of patients with untreated idiopathic scoliosis: a 50-year natural history study. JAMA, 2003, 289: 559-567. [Medline] [CrossRef]

6) Hensinger RN: Congenital anomalies of the cervical spine. Clin Orthop Relat Res, 1991, (264): 16-38. [Medline]

7) Janicki JA, Alman B: Scoliosis: review of diagnosis and treatment. Paediatr Child Health (Oxford), 2007, 12: 771-776. [Medline]

8) Daruwalla JS, Balasubramaniam P, Chay SO, et al.: Idiopathic scoliosis. Prevalence and ethnic distribution in Singapore school children. J Bone Joint Surg Br, 1985, 67: 182-184. [Medline]

9) Lonstein JE, Bjorklund S, Wanninger MH, et al.: Voluntary school screening for scoliosis in Minnesota. J Bone Joint Surg Am, 1982, 64: 481-488. [Medline]

10) Bonagamba GH, Coelho DM, Oliveira AS: Inter and intra-rater reliability of the scoliometer. Rev Bras Fisioter, 2010, 14: 432-438. [Medline] [CrossRef]

11) Bunnell WP: The natural history of idiopathic scoliosis before skeletal maturity. Spine, 1986, 11: 773-776. [Medline] [CrossRef]

12) Jackson RP, McManus AC: Radiographic analysis of sagittal plane alignment and balance in standing volunteers and patients with low back pain matched for age, sex, and size. A prospective controlled clinical study. Spine, 1994, 19: 1611-1618. [Medline] [CrossRef]

13) Neumann DA: Kinesiology of the Musculoskeletal System: Foundations for Physical Rehabilitation. Philadelphia: Mosby, 2002.

14) Jang JS, Lee SH, Kim JM, et al.: Can patients with sagittally well-compensated lumbar degenerative kyphosis benefit from surgical treatment for intractable back pain? Neurosurgery, 2009, 64: 115-121, discussion 121. [Medline] [CrossRef]

15) Jang JS, Lee SH, Min JH, et al.: Lumbar degenerative kyphosis: radiologic analysis and classifications. Spine, 2007, 32: 2694-2699. [Medline] [CrossRef]

16) Park JY, Park GD, Lee SG, et al.: The effect of scoliosis angle on center of gravity sway. J Phys Ther Sci, 2013, 25: 1629-1631. [Medline] [CrossRef]

17) Legaye J, Duval-Beaupère G: Sagittal plane alignment of the spine and gravity: a radiological and clinical evaluation. Acta Orthop Belg, 2005, 71: 
213-220. [Medline]

18) Labelle H, Roussouly P, Berthonnaud E, et al.: The importance of spinopelvic balance in L5-s1 developmental spondylolisthesis: a review of pertinent radiologic measurements. Spine, 2005, 30: S27-S34. [Medline] [CrossRef]

19) Vialle R, Levassor N, Rillardon L, et al.: Radiographic analysis of the sagittal alignment and balance of the spine in asymptomatic subjects. J Bone Joint Surg Am, 2005, 87: 260-267. [Medline] [CrossRef]

20) Martin PE: Mechanical and physiological responses to lower extremity loading during running. Med Sci Sports Exerc, 1985, 17: 427-433. [Medline] [CrossRef]

21) Susan AS: Uptodate. Clinical features; evaluation; and diagnosis of adolescent idiopathic scoliosis. www.uptodate.com/contents/ clinical-features-evaluationand-diagnosis-of-adolescent-idiopathicscoliosis? source $=$ search_result\&search $=$ scoliosis \&selectedTitle $=1 \%$ 7E150 (Accessed Dec. 24, 2012)

22) Lee S, Shim J: The effects of backpack loads and spinal stabilization exercises on the dynamic foot pressure of elementary school children with idiopathic scoliosis. J Phys Ther Sci, 2015, 27: 2257-2260. [Medline] [CrossRef]

23) Kouwenhoven JW, Castelein RM: The pathogenesis of adolescent idiopathic scoliosis: review of the literature. Spine, 2008, 33: 2898-2908. [Medline] [CrossRef]

24) Fortin C, Feldman DE, Cheriet F, et al.: Reliability of a quantitative clinical posture assessment tool among persons with idiopathic scoliosis. Physiotherapy, 2012, 98: 64-75. [Medline] [CrossRef]

25) Buchecker M, Stöggl T, Müller E: Spine kinematics and trunk muscle activity during bipedal standing using unstable footwear. Scand J Med Sci Sports, 2013, 23: e194-e201. [Medline] [CrossRef]

26) Weinstein SL: Adolescent idiopathic scoliosis: prevalence and natural history. Instr Course Lect, 1989, 38: 115-128. [Medline]

27) Morrissy RT: School screening for scoliosis. Spine, 1999, 24: 2584-2591. [Medline] [CrossRef]

28) Lonstein JE: Screening for spinal deformities in Minnesota schools. Clin Orthop Relat Res, 1977, (126): 33-42. [Medline] 